\title{
EFFECTS OF ATMOSPHERIC CORROSION ON THE CAR PARK ROOF STRUCTURE
}

The effects of the outdoor climatic conditions are observed in all constructions. Steel members of such constructions are affected negatively by urban atmospheres in a synergy with the effects of industrial pollutants. In very exposed buildings the impact of such effects is so significant that diagnostic assessment of their state and technical expertise is required.

The paper presented shows the actual state assessment and the verification of structural reliability of the existing load-bearing structure of an exterior car park roof, emphasizing the estimation of corrosion losses in the steel structure that have considerably lowered its lifespan and obstructed its safe operation.

Keywords: Atmospheric corrosion, steel structure, spectrometer, deviations, degradation analysis, chemical analysis.

\section{Introduction}

The observation of steel degradation in adverse atmospheric conditions has been the subject of a number of scientific papers and specialized publications, the effects of the atmosphere in the city of Košice on various constructions are no exception. The atmospheric conditions in the city are somewhat specific as both urban and industrial activities can be observed. Since the 1970s there has been an extended research programme into the effects of atmospheric corrosion on the mechanical properties and surface morphology of some selected exposed steel specimens of the weathering steel Atmofix [1]. Similarly, due to the extensive use of the Konox steel, the long-term monitoring of the atmospheric influence on some exposed specimens took place for a period of 20 years [2] Besides, steel corrosion products of galvanic corrosion have been studied [3]. Some foreign research studies pertained to the longterm negative effects of various types of atmosphere (rural, urban, and industrial) during the 13-year-long exposure period where structural changes and the morphology of corrosive neo-formations were investigated [4]. Other studies dealt with the effects of a tropical marine environment on metal elements [5]. Numerous research programmes have also pertained to the effects of atmospheric conditions on historical monuments, for instance, the state of the Dehli iron pillar in India has been monitored for quite long $[6,7,8]$. As the long-term monitoring of the corrosion processes in steel members is too costly, numerous corrosion tests are undertaken on models simulating the aggressive environmental conditions, and, in specifically defined conditions, research into the kinetics of corrosion phenomena is possible.

From the methodological point of view, progressive analytical methods are preferred for the identification and quantification of the material damage rate in order to minimize destruction and further structural disturbances, or complex non-destructive tests in situ are used.

In diagnostic tests of exposed elements it is necessary to assess the state of construction in full, not only examine its degraded parts. The goal of the work in question was a complex analysis and state assessment of selected steel members in the car park roof structure of the University Hospital in Košice at Trieda SNP 1. This building needs to be continuously monitored as there is permanent movement of patients and staff. The condition of the roof structure was assessed partly on the basis of the results of non-destructive testing on corrosion losses of steel in situ. Consequently, some selected particularly rusted samples were collected and analysed using chemometric techniques.

\section{Technical specifications of the building}

The construction of the building situated in the suburban part of Košice-Západ took place between 1973 and 1981. The construction is strongly affected by the urban pollutants produced by nearby industries and heavy traffic. The prevailing northerly and northwesterly air circulation in the area causes natural driftage of solid particles so far as to the area of the car park (Figs. 1a, 1b). In the past, the location was directly affected by the pollution produced by a magnesite-processing factory and the effects of these pollutants on building constructions were purposefully investigated [9].

The structure itself is divided into two separate structural units - internal and external roof structures (Fig. 1).

\footnotetext{
* Vincent Kvocak ${ }^{1}$, Renata Vargova ${ }^{2}$, Pavol Beke ${ }^{3}$, Eva Terpakova ${ }^{4}$

${ }^{1}$ Faculty of Civil Engineering, Technical University of Kosice, Slovakia, E-mail: vincent.kvocak@tuke.sk
} 

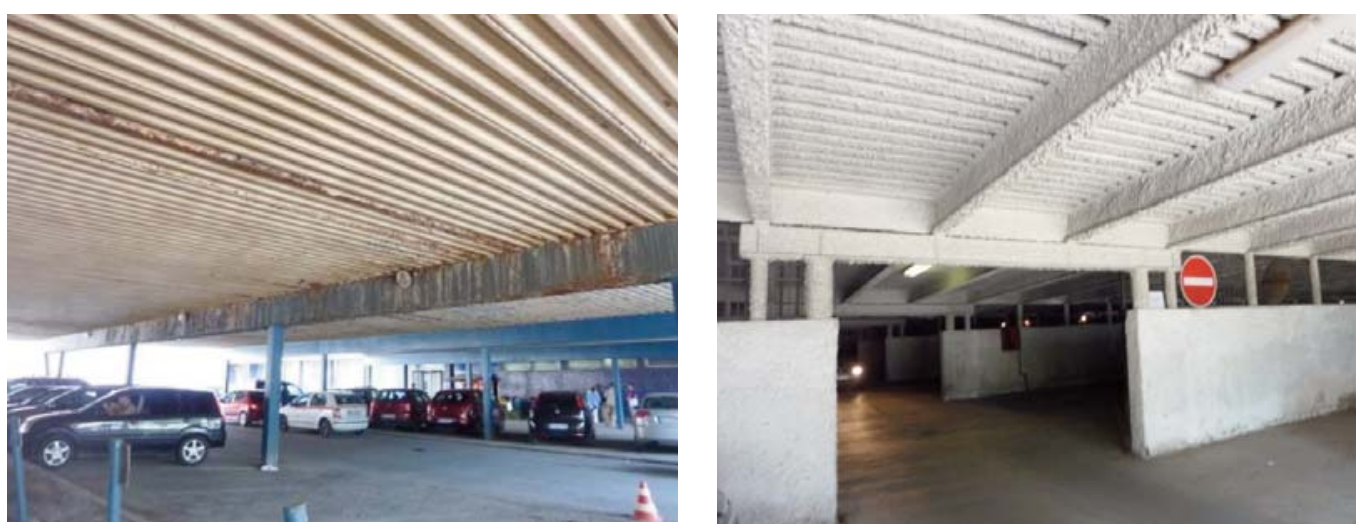

Fig. 1 The external (left) and the internal (right) roof structures of the University Hospital car park, Kosice, Trieda SNP 1

The external roof structure consists of seven steel frames. The cross-beams in Frame 1 and Frame 5 are formed of hollow rectangular sections, $0.6 \mathrm{~m}$ in length. The cross-beam of Frame 6 is formed of a rolled-steel I-section with the same height of $0.6 \mathrm{~m}$, braced in a distance of approximately $1.6 \mathrm{~m}$. Between Frames 5 and 6 there is a movement joint dividing the external and internal car park roof structures allowing reversible cyclic movement in building materials. In a distance of approximately $8.0 \mathrm{~m}$ the steel beams of the frames of the external structure are supported by columns made from hollow sections.

The load-bearing structure of the internal car park roof consists of open I-sections, $0.34 \mathrm{~m}$ high in a distance of $1.6 \mathrm{~m}$. All steel cross-beams in the examined frames are supported by short columns formed of hollow circular sections embedded on a monolithic wall. The axial distance between the walls is $8.0 \mathrm{~m}$. All the beams in the internal roof structure are provided with protective sprayed coating.

\section{Assessment methodology}

As the extent of the damage was quite extensive, attention was directed primarily to the measurements of the actual geometric proportions of the individual steel members. The geometric proportions in each field of the examined frame were experimentally verified, especially in the regions with the most serious local damage of the beams, i.e. in the locations that were the most important for the global structural analysis and state assessment. The height $-h[\mathrm{~mm}]$, width $-b[\mathrm{~mm}]$, and web thickness $-t_{w}[\mathrm{~mm}]$ of the sections were detected, and in open beams, the flange thickness $-t_{f}[\mathrm{~mm}]$ as well. The geometric proportions for all steel sections were measured directly using an ultrasonic thickness gauge ELCOMETER, Type R56887 and a digital meter with a range from 0 to $150 \mathrm{~mm}$ and precision of $\pm 0.02 \mathrm{~mm}$.

All changes in material characteristics were simultaneously analysed in mechanically collected samples. The elemental analysis of surface layers of steel sheets was reformed by X-ray fluorescence (XRF) using an AMETEK Spectro iQ II spectrometer.
Concurrently, the chemical elements were analysed in the water extract/leachate prepared to determine its alkalinity. The content of water-soluble chlorides was measured using a potentiometer. Hydrogen ion concentration ( $\mathrm{pH}$-value) was measured by an Acidimeter 333. Chloride concentration was determined by the ion-selective chloride electrode (ISE), while for comparison, the RC102 electrode was used. Extracts were made in deionised water with a conductivity of $0.02 \mathrm{mS}$ and a deioniser RODEM 6 was used to prepare deionised water.

The quality of rust samples was characterised by Fourier transform infrared spectroscopy (FTIR) using an Alfa Brucker Platinum - ATR FTIR. Measurements were undertaken in the $360-4000 \mathrm{~cm}^{-1}$ wavelength range, and each specimen was scanned 24 times with a resolution of lines of $4 \mathrm{~cm}^{-1}$.

\section{Experimental procedure}

On visual on-site inspection of the existing structures it was concluded that Beams 1, 2 and 4 did not exhibit any signs of damage. It was further concluded that they were reliable and safe. The reason for their well-preserved condition might be their original good quality. On the contrary, Beams 3, 5 and 6 were greatly affected by corrosion, so it was essential to assess their real state, determine the actual corrosion losses in the individual fields of the examined beams as well as to examine the effects of external factors. The condition of the above-mentioned beams is shown in Figs. 2 and 3.

\subsection{Measurements of actual geometric proportions and cross-sections}

Measurements were carried out alongside the beam in three independent sections - in the centre and at both ends of each field. Similarly, three measurements were undertaken along the web height. Measurements (Fig. 2) were carried out on the web and both flanges of the steel sections. In each selected location three independent measurements were made. For further assessments of 

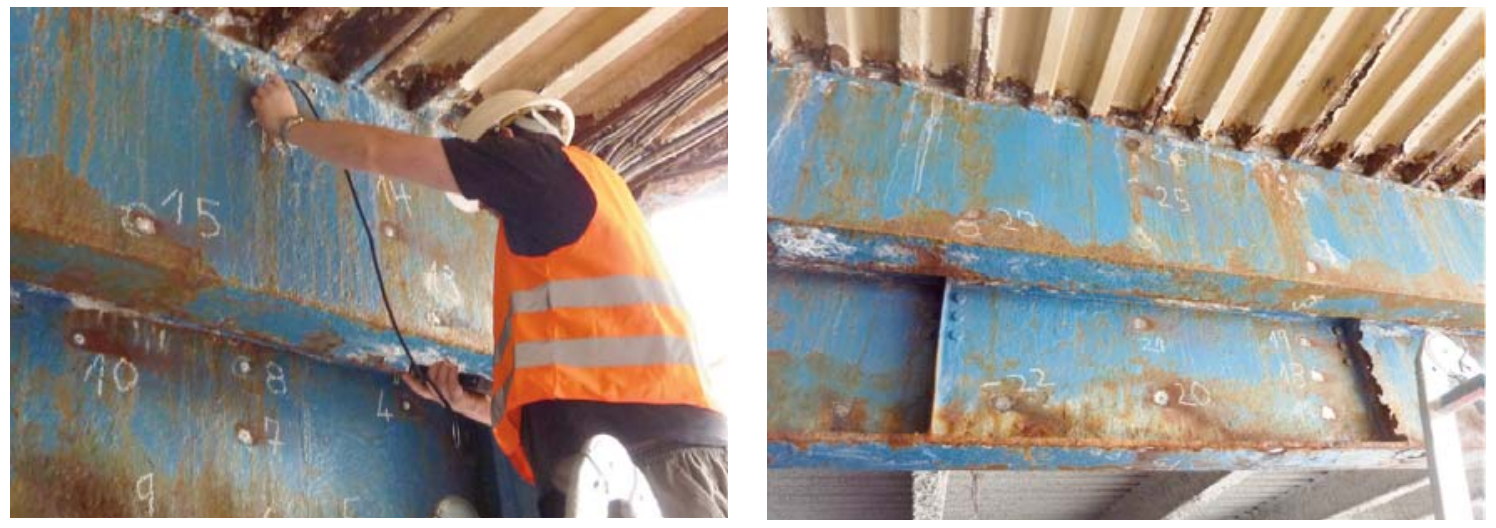

Fig. 2 Experimental measurements of the section thickness of Beam 6 in the most exposed locations

the existing steel beams, the average values of the geometric proportions from all measurements were used. Based on the obtained results, a database of input data was created, necessary for the calibration of theoretical models and for some future measures to be adopted in order to fully refurbish the steel structure.

Some partial results - some selected values from the experimental measurements in the most damaged Beam 6 - and the deviations from the values declared in the design are documented in Tables 1 and 2. All experimental results are part of the complex technical expertise [10].

Measurements and the following evaluation of the measured geometric proportions are one of the most valuable instruments in the reliability assessment of existing steel structures and members. Potential variations in the dimensions of steel sections considerably influence their section properties, which eventually affect the overall resistance and deformation of a steel structure [10, 11 and 17]. Therefore, geometric proportions should always comply with the standard tolerances.

In this view, all geometric properties measured were statistically analysed and subsequently compared with the allowable tolerances stipulated by the STN EN 10029+AC [12] and STN EN 1090-2 [13]. The dimensions of the cross-sections were used to calculate the relevant section properties and the actual resistance of the steel structure according to the STN EN 1993-1-1 [14]. As a result, appropriate measures were proposed to renovate the steel structure examined.

As expected, the most substantial deviations were detected in Beam 6. Degradation of its braces was evident, the flange and web thicknesses in the indicated locations remarkably reduced. The corrosion losses in the thickness of the lower flange were most dramatic - up to $6 \mathrm{~mm}$. Similarly, serious losses occurred in the web, namely in the first field, from the original $8 \mathrm{~mm}$ to barely $5 \mathrm{~mm}$. Due to the degradation effects of the environment most of the braces (the shear reinforcement) in the beam were damaged leading to a significant decrease in its shear resistance.
All diagnosed degradation effects had substantially reduced the load-bearing capacity of all steel members and thus jeopar-

Average values of geometric proportions

Table 1 in Cross-section 6 (the web)

\begin{tabular}{|c|c|c|c|c|c|c|c|}
\hline \multirow{2}{*}{ Field } & \multirow{2}{*}{$\begin{array}{l}\text { Loca- } \\
\text { tion }\end{array}$} & \multicolumn{3}{|c|}{ Measurement [mm] } & \multirow{2}{*}{$\begin{array}{c}\text { Diameter } \\
{[\mathrm{mm}]}\end{array}$} & \multirow{2}{*}{$\begin{array}{c}\text { Declared } \\
\text { value } \\
\text { [mm] }\end{array}$} & \multirow{2}{*}{$\begin{array}{c}\text { Devia } \\
\text { tions }\end{array}$} \\
\hline & & 1 & 2 & 3 & & & \\
\hline \multirow{9}{*}{1.} & 1 & 5.3 & 5.2 & 5.4 & 5.3 & \multirow{9}{*}{8} & -2.7 \\
\hline & 2 & 5.3 & 5.3 & 5.3 & 5.3 & & -2.7 \\
\hline & 3 & 6 & 5.9 & 5.8 & 5.9 & & -2.1 \\
\hline & 4 & 4.8 & 4.6 & 5.3 & 4.9 & & -3.1 \\
\hline & 5 & 7 & 7.3 & 7.3 & 7.2 & & -0.8 \\
\hline & 6 & 5.7 & 5.8 & 5.6 & 5.7 & & -2.3 \\
\hline & 7 & 6 & 5.8 & 5.9 & 5.9 & & -2.1 \\
\hline & 8 & 7.1 & 7.1 & 7.4 & 7.2 & & -0.8 \\
\hline & 9 & 5 & 5.3 & 5.3 & 5.2 & & -2.8 \\
\hline \multirow{3}{*}{2.} & 10 & 7.2 & 7.5 & 7.5 & 7.4 & \multirow{3}{*}{8} & -0.6 \\
\hline & 11 & 7.8 & 7.8 & 7.8 & 7.8 & & -0.2 \\
\hline & 12 & 7.3 & 7.3 & 7.4 & 7.3 & & -0.7 \\
\hline \multirow{6}{*}{3.} & 13 & 8.1 & 8.1 & 8.2 & 8.1 & \multirow{6}{*}{8} & +0.1 \\
\hline & 14 & 8.2 & 8.2 & 8.2 & 8.2 & & +0.2 \\
\hline & 15 & 8 & 8 & 8 & 8.0 & & \pm 0.0 \\
\hline & 16 & 7.8 & 7.8 & 7.9 & 7.8 & & -0.2 \\
\hline & 17 & 7.6 & 7.5 & 7.7 & 7.6 & & -0.4 \\
\hline & 18 & 7.5 & 7.4 & 7.4 & 7.4 & & -0.6 \\
\hline \multirow{5}{*}{4.} & 19 & 7.9 & 7.9 & 8 & 7.9 & \multirow{5}{*}{8} & -0.1 \\
\hline & 20 & 8.1 & 8.2 & 8.2 & 8.2 & & +0.2 \\
\hline & 21 & 8.2 & 8.2 & 8.2 & 8.2 & & +0.2 \\
\hline & 22 & 8.1 & 8.1 & 8.1 & 8.1 & & +0.1 \\
\hline & 23 & 8.2 & 8.2 & 8.2 & 8.2 & & +0.2 \\
\hline
\end{tabular}




\begin{tabular}{|c|c|c|c|c|c|c|c|}
\hline \multirow{7}{*}{5.} & 24 & 7.7 & 7.8 & 7.8 & 7.8 & \multirow{7}{*}{8} & -0.2 \\
\hline & 25 & 6.6 & 6.6 & 6.5 & 6.6 & & -1.4 \\
\hline & 26 & 6.6 & 6.6 & 6.5 & 6.6 & & -1.4 \\
\hline & 27 & 7.4 & 7.3 & 7.3 & 7.3 & & -0.7 \\
\hline & 28 & 7.9 & 7.8 & 7.7 & 7.8 & & -0.2 \\
\hline & 29 & 6.9 & 6.8 & 6.8 & 6.8 & & -1.2 \\
\hline & 30 & 5.6 & 5.5 & 5.5 & 5.5 & & -2.5 \\
\hline \multirow{5}{*}{6.} & 31 & 7.7 & 7.7 & 7.7 & 7.7 & \multirow{5}{*}{8} & -0.3 \\
\hline & 32 & 7.6 & 7.5 & 7.6 & 7.6 & & -0.4 \\
\hline & 33 & 7.8 & 7.8 & 7.8 & 7.8 & & -0.2 \\
\hline & 34 & 7.8 & 7.9 & 7.8 & 7.8 & & -0.2 \\
\hline & 35 & 7.9 & 7.8 & 7.7 & 7.8 & & -0.2 \\
\hline
\end{tabular}

dized the safety of the building as a whole. By their nature and geometry, the examined beams did not meet the requirements for safe and reliable occupancy of the building any longer; therefore, measures for its renovation were inevitably proposed and implemented.

\subsection{Degradation analysis}

The rate of degradation of steel members was determined on mechanically removed rust samples from Beam 6 whose material was badly corroded, flaky, non-compact. The details of the sample surface are documented in Fig. 4. An optical microscope BRESSER was used to assess corrosive changes in the samples in great detail. At only the magnification of 20 (Fig. 5 left), both pitting and surface corrosion was indicated resulting in the separation of layers of rust. In Fig. 5 on the right, there is a detail of the same surface magnified $80 \times$ where a deep microcrack can be seen with evident surface corrosion.

As the samples of metal material were seriously degraded, attention was focused on the description of corrosion products.

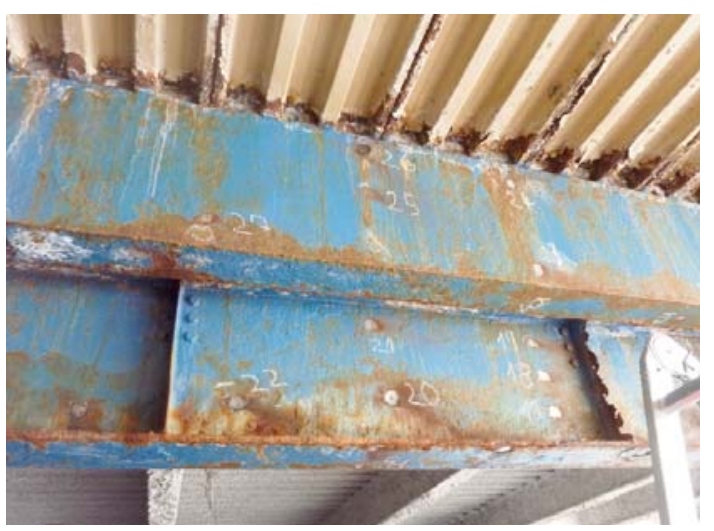

Average values of geometric proportions in Cross-section 6 (the flange)

\begin{tabular}{|c|c|c|c|c|c|c|c|}
\hline \multirow{2}{*}{ Field } & \multirow{2}{*}{$\begin{array}{l}\text { Loca- } \\
\text { tion }\end{array}$} & \multicolumn{3}{|c|}{ Measurement $[\mathrm{mm}]$} & \multirow{2}{*}{$\begin{array}{c}\text { Diameter } \\
{[\mathrm{mm}]}\end{array}$} & \multirow{2}{*}{$\begin{array}{c}\text { Declared } \\
\text { value } \\
{[\mathrm{mm}]}\end{array}$} & \multirow{2}{*}{$\begin{array}{l}\text { Devia- } \\
\text { tions }\end{array}$} \\
\hline & & 1 & 2 & 3 & & & \\
\hline \multirow{3}{*}{1.} & $1 \mathrm{P}$ & 14.3 & 14.1 & 14.5 & 14.3 & \multirow{3}{*}{20} & -5.7 \\
\hline & $2 \mathrm{P}$ & 14.8 & 15 & 15.2 & 15 & & -5.0 \\
\hline & $3 \mathrm{P}$ & 15.3 & 15.7 & 15.8 & 15.6 & & -4.4 \\
\hline \multirow{3}{*}{2.} & $4 \mathrm{P}$ & 16.8 & 16.8 & 16.6 & 16.7 & \multirow{3}{*}{20} & -3.3 \\
\hline & $5 \mathrm{P}$ & 16.4 & 16.4 & 16.4 & 16.4 & & -3.6 \\
\hline & $6 \mathrm{P}$ & 16.7 & 16.6 & 16.8 & 16.7 & & -3.3 \\
\hline \multirow{3}{*}{3.} & $7 \mathrm{P}$ & 15.6 & 15.8 & 15.7 & 15.7 & \multirow{3}{*}{20} & -4.3 \\
\hline & $8 \mathrm{P}$ & 19 & 19.1 & 18.7 & 18.9 & & -1.1 \\
\hline & 9P & 15.6 & 15.7 & 15.6 & 15.6 & & -4.4 \\
\hline \multirow{3}{*}{4.} & 10P & 17.5 & 17.5 & 17.6 & 17.5 & \multirow{3}{*}{20} & -2.5 \\
\hline & $11 \mathrm{P}$ & 16.9 & 17.2 & 17.3 & 17.1 & & -2.9 \\
\hline & $12 \mathrm{P}$ & 18.3 & 18.3 & 18.3 & 18.3 & & -1.7 \\
\hline \multirow{3}{*}{5.} & $13 \mathrm{P}$ & 20.3 & 20.3 & 20.3 & 20.3 & \multirow{3}{*}{20} & +0.3 \\
\hline & $14 \mathrm{P}$ & 14.7 & 14.7 & 14.7 & 14.7 & & -5.3 \\
\hline & $15 \mathrm{P}$ & 17.1 & 17.1 & 17 & 17.1 & & -2.9 \\
\hline 6. & $13 \mathrm{P}$ & 17.7 & 17.8 & 17.7 & 17.7 & 20 & -2.3 \\
\hline
\end{tabular}

All samples were rather damp after the collection so they had to be dried out before the experiments at a temperature of $105 \pm 5^{\circ} \mathrm{C}$ in a laboratory furnace ELOP 1200/15.

\subsubsection{Alkalinity of leachates from corrosive products}

The presence of inorganic compounds was anticipated in all examined corrosion products layering the structure of the material. As their solubility is very individual, leachates/water extracts from three separated representative products were made and, under the

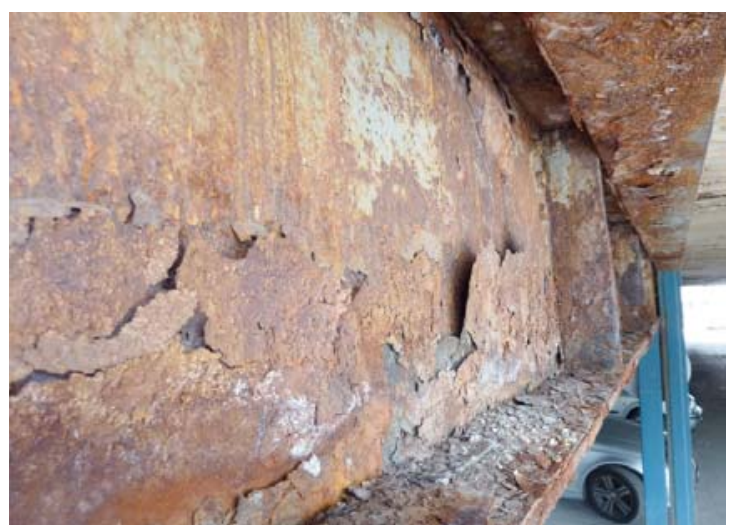

Fig. 3 Views of the steel frame details of the external car park roof structure (the condition before the renovation) 

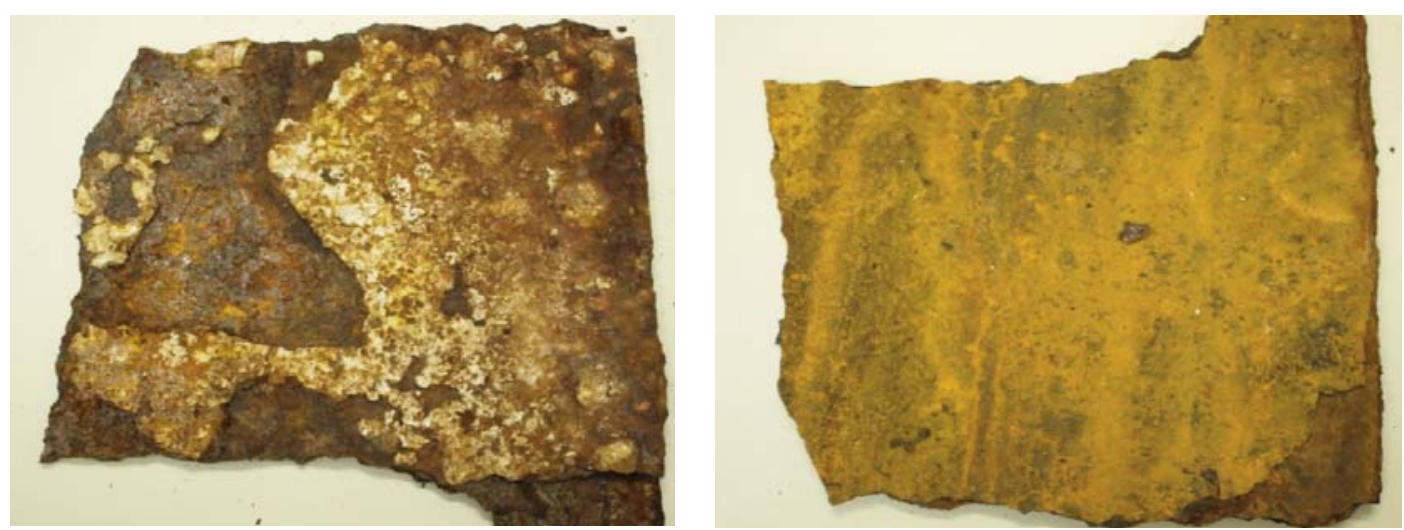

Fig. 4 Appearance of the external part of the sample (on the left) and of the reverse side of the sample (on the right) with the residues of coating
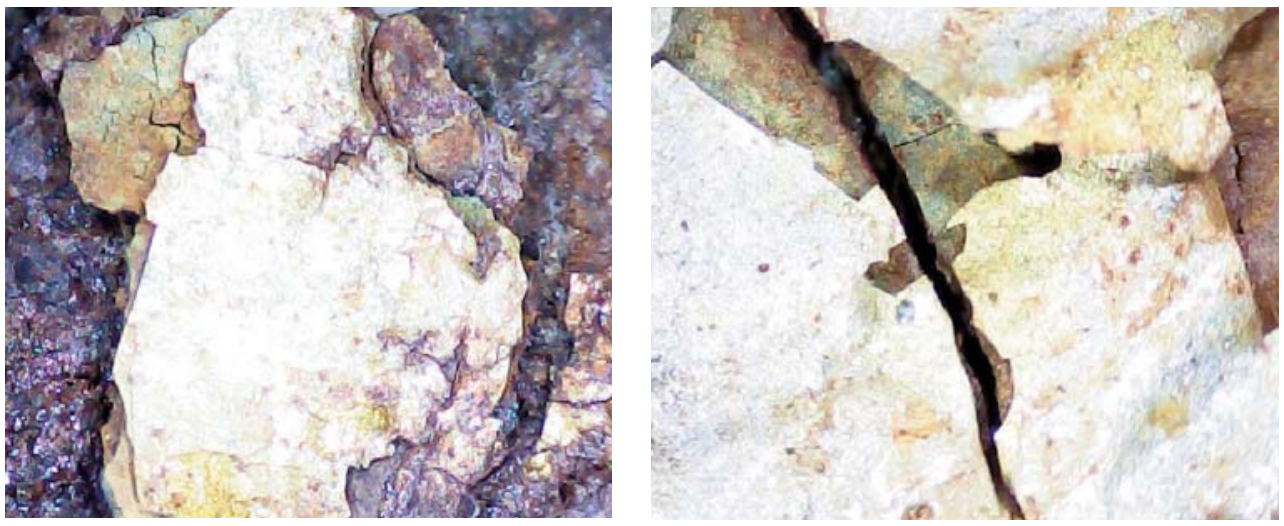

Fig. 5 Micrograph of the sample surface - magnified 20x (on the left), serious surface corrosion evident under a microcrack -at the magnification of 80 (on the right)

static conditions, at a laboratory temperature of $22 \pm 2{ }^{\circ} \mathrm{C}$, $\mathrm{pH}$-values of the extracts were determined after 1, 3 and 24 hours and then after 7 and 21 days (Table 3). Part of the garage construction contains a trafficable roof; therefore the presence of chlorides from the environment due to water leakage was anticipated as well. Hence, the samples were tested for the concentration of chloride ions.

\subsubsection{Chemical analysis of corrosion products}

Atomic emission spectrometry (AES), atomic absorption spectrometry (AAS), optical emission spectrometry with inductively coupled plasma (OES-ICP) and several other methods meeting the requirements for precision and correctness of analytical outputs are suitable for the determination of the quantity of corrosion products

\begin{tabular}{|l|c|c|c|c|c|}
\hline \multirow{2}{*}{} & \multicolumn{5}{|c|}{$\mathrm{pH}[-]$} \\
\cline { 2 - 6 } & 1hour & 3 hours & 6 hours & $7 \times 24$ hours & $21 \times 24$ hours \\
\hline Surface regions up to 0-1mm & $7.22 \pm 0.01$ & $7.39 \pm 0.01$ & $7.48 \pm 0.01$ & $7.89 \pm 0.01$ & $8.13 \pm 0.03$ \\
\hline Central regions 1-3mm & $7.15 \pm 0.01$ & $7.15 \pm 0.01$ & $7.37 \pm 0.01$ & $7.56 \pm 0.01$ & $8.17 \pm 0.01$ \\
\hline$<3 \mathrm{~mm}$ & $7.08 \pm 0.01$ & $7.17 \pm 0.01$ & $7.29 \pm 0.01$ & 7.500 .01 & $7.99 \pm 0.01$ \\
\hline & \multicolumn{6}{|c|}{ Chloride concentrations [ mol. $\left.{ }^{-1}\right]$} \\
\hline Surface regions up to 0-1mm & 0.01 & 0.023 & 0.034 & 0.052 & 0.078 \\
\hline Central regions 1-3mm & 0.01 & 0.022 & 0.033 & 0.055 & 0.079 \\
\hline$<3 \mathrm{~mm}$ & 0.005 & 0.021 & 0.030 & 0.054 & 0.078 \\
\hline
\end{tabular}




\begin{tabular}{|c|c|c|c|c|}
\hline Constituent elements & $\begin{array}{c}\text { Ao } \\
\text { Surface - protective layer } \\
{[\%] \pm \text { absolute error }}\end{array}$ & $\begin{array}{c}\text { A } \\
\text { Surface under the protective } \\
\text { layer }[\%] \pm \text { absolute error }\end{array}$ & $\begin{array}{c}\text { B } \\
\text { Leached surface [\%] } \\
\pm \text { absolute error }\end{array}$ & $\begin{array}{l}\text { 7-day leachate }\left[\mathrm{mg} \cdot \mathrm{kg}^{-1}\right] \\
\pm \text { absolute error }\end{array}$ \\
\hline $\mathrm{Fe}$ & $94.29 \pm 0.07$ & $98.11 \pm 0.06$ & $97.78 \pm 0.07$ & $176.5 \pm 2.0$ \\
\hline $\mathrm{Zn}$ & $2.213 \pm 0.010$ & $<0.0023 \pm 0.0017$ & $0.2637 \pm 0.0036$ & $31.2 \pm 0.8$ \\
\hline $\mathrm{Ti}$ & $0.5940 \pm 0.0024$ & $0.00627 \pm 0.00073$ & $0.00521 \pm 0.00072$ & $10.1 \pm 0.1$ \\
\hline $\mathrm{Mn}$ & $0.4675 \pm 0.0053$ & $0.4828 \pm 0.0044$ & $0.6722 \pm 0.0048$ & $45.5 \pm 3.6$ \\
\hline $\mathrm{Al}$ & $0.4876 \pm 0.0054$ & $0.1329 \pm 0.0025$ & $0.0678 \pm 0.0034$ & $700 \pm 12$ \\
\hline $\mathrm{Cr}$ & $0.1564 \pm 0.0022$ & $0.1957 \pm 0.0018$ & $0.1780 \pm 0.0018$ & $<5.1 \pm(0.0$ \\
\hline V & $0.0463 \pm 0.0015$ & $0.00111 \pm 0.00058$ & $0.01170 \pm 0.00062$ & $<5.1 \pm(0.0)$ \\
\hline$P$ & $0.01177 \pm 0.00085$ & $0.01008 \pm 0.00043$ & $0.00260 \pm 0.00052$ & $17.5 \pm 1.1$ \\
\hline $\mathrm{Ga}$ & $0.2025 \pm 0.0032$ & $0.0777 \pm 0.0027$ & $0.1829 \pm 0.0027$ & $<1.0 \pm(0.0$ \\
\hline Mo & $0.00618 \pm 0.00068$ & $0.01068 \pm 0.00055$ & $0.00367 \pm 0.00048$ & $<10$ \\
\hline $\mathrm{Pb}$ & $0.2785 \pm 0.0043$ & $0.2346 \pm 0.0035$ & $0.01356 \pm 0.00066$ & $<2.0 \pm(0.01)$ \\
\hline $\mathrm{Ba}$ & - & - & - & $54 \pm 2.0$ \\
\hline $\mathrm{Sr}$ & - & - & - & $0.7 \pm 0.3$ \\
\hline \multicolumn{5}{|c|}{ Supplementary elements } \\
\hline Co & $<0.00030$ & $<0.00030$ & $<0.00030$ & $3.3 \pm 0.7$ \\
\hline $\mathrm{Ni}$ & $<0.00020$ & $<0.00020$ & $<0.00020$ & $<2.0$ \\
\hline $\mathrm{Cu}$ & $<0.00010$ & $0.0450 \pm 0.0038$ & $<0.00010$ & $16.8 \pm 1.3$ \\
\hline $\mathrm{Cd}$ & $<0.00051$ & $<0.00051$ & $<0.00051$ & $<20$ \\
\hline \multicolumn{5}{|c|}{ Environmental elements } \\
\hline S & $0.5452 \pm 0.0014$ & $0.1208 \pm 0.0007$ & $0.5236 \pm 0.0011$ & $117.3 \pm 0.9$ \\
\hline $\mathrm{Si}$ & $0.4296 \pm 0.0029$ & $0.4324 \pm 0.0021$ & $0.1821 \pm 0.002$ & $1704 \pm 9$ \\
\hline $\mathrm{Ca}$ & $0.2758 \pm 0.0026$ & $0.0947 \pm 0.0015$ & $0.0973 \pm 0.0015$ & $669.1 \pm 5.3$ \\
\hline $\mathrm{Mg}$ & $<0.0010$ & $0.0252 \pm 0.0089$ & $<0.0010$ & $<101 \pm 1.8$ \\
\hline $\mathrm{Cl}$ & $<0.010$ & $<0.010$ & $<0.010$ & $668.9 \pm 1.8$ \\
\hline K & $<0.0010$ & $<0.0010$ & $<0.0010$ & $<10$ \\
\hline
\end{tabular}

[12]. In order to eliminate the influence of chemical decomposition, $\mathrm{X}$-ray fluorescence analysis (XRF) was used where a solid sample removed from the surface can be directly excited by fluorescence radiation.

Samples of approximate size $15 \times 15 \times 2.5 \mathrm{~mm}$ were cut from the steel sheets and used for further analyses. Measurements were performed by an XRF SPECTRO iQ II spectrometer (supplied by Brucker of Germany).

$\mathrm{XRF}$ analysis is limited to elements of a proton number $<11$ i.e. it is basically possible to analyse all dominant elements of the metal matrix from $11 \mathrm{Na}$ as well as inorganic pollutants collected from the environment. Unfortunately, due to its limitations, it is impossible to quantify and analyse carbon.

Besides the analysis of solid samples, chemical analysis of leachates was made after a 7-day period when the steel sheet sample was leached in $100 \mathrm{ml}$ of deionised water. The average results of three measurements are shown in Table 4.

The material characteristics of the individual members of the examined steel structure were adopted from the original design documentation stating the fact that Steel S235 was used. For the purpose of comparison of the material composition of the examined specimens (Table 4), the steel composition compliant with the relevant standard specifications and technical regulations is listed in Table 5.

\section{Discussion}

The atmospheric conditions in the city of Košice are typical of a specific mixed urban-industrial polluted environment. Nowadays, it is particularly influenced by the emissions produced by the integrated iron-and-steelworks plant of US STEEL a. s., however, 


\begin{tabular}{|lc|c|c|c|c|c|c|}
\hline \multicolumn{2}{|c|}{ Steel } & \multicolumn{6}{|c|}{ \% Representation } \\
\cline { 3 - 8 } & & $\mathrm{C}$ & $\mathrm{Si}$ & $\mathrm{Mn}$ & $\mathrm{P}$ & $\mathrm{S}$ & $\mathrm{Cu} . \mathrm{Ni}$ Cr \\
\hline S 235 & {$[15]$} & $0.09-0.19$ & Not stated & $0.25-0.40$ & max.0.04 & max. 0.04 & max. 0.3 \\
\hline Steel S235 & {$[16]$} & 0.16 & 0.35 & 1.2 & 0.03 & 0.025 & not stated \\
\hline Steel S235JRH & {$[16]$} & 0.17 & - & 1.4 & 0.045 & 0.045 & not stated \\
\hline
\end{tabular}

in the past the second greatest polluter in the region was the Slovak magnesite-processing factory.

The long-term effects of these two major polluters on the surrounding environment have been studied using various chemometric techniques. The influence of the outdoor conditions on the corrosion of model specimens investigated in the studies [1-4] has confirmed the necessity for the development of corrosion-resistant steels and/or their secondary protection using appropriate corrosion control technologies. The corrosion process in steel depends on a number of different factors: steel production technology, its chemistry, carbon contents, the quantity and quality of alloying elements, to mention but a few. In addition, in atmospheric corrosion, the concentrations of various pollutants, thermal and humidity conditions having an impact on material properties must be taken into consideration. In the construction of the car park roof the influence of all sorts of pollutants were present, such as $\mathrm{SO}_{2}$, $\mathrm{SO}_{3}, \mathrm{H}_{2} \mathrm{~S}, \mathrm{NO}_{\mathrm{x}}, \mathrm{CO}, \mathrm{CO}_{2}$., $\mathrm{NH}_{4}^{+}$etc.; condensation and percolation water, but also solid pollutants containing $\mathrm{Mg}^{+2}$ compounds, microparticles, dust and fly ashes etc.

Specific effects in the city are caused by exhaust emissions from heavy traffic and by road salt spread on access roads to melt snow during the winter season. The analyses indicated chloride concentrations in the corrosion product leachates as high as $668.9 \pm$ $1.8 \mathrm{mg} \cdot \mathrm{kg}^{-1}$. Obviously, this fact reflected in very notable changes in the physico-chemical characteristics and the functionality of the metal members. It is generally known that the commonest cause of electrochemical corrosion is the exposure of metals to chlorides. The corrosion kinetics depends also on the composition of the steel member, presence of alloying elements, and humidity and temperature variations. Corrosion advances with the accumulation of microscopic layers of rusts on a steel surface.

The principal source of sulphuric ions is the atmosphere and rainfall. The sulphur concentrations determined in both metal sample leachates and solid samples undoubtedly proved this fact. In comparison with the declared standard concentrations [16], where the maximum overall sulphur content is given at $0.045 \%$, the actual sulphur concentrations in the samples were from 10 to 12 times higher.

In agreement with the assumptions, the Mg-O stretching vibrations ( 668 and $479 \mathrm{~cm}^{-1}$ ) were identified, which only confirmed the environmental influence of magnesite processing even in the course of several years.

\section{Conclusion}

The aim of the paper presented was to assess the actual state of the existing load-bearing steel structure of the car park roof of the University Hospital in Koice from the point of view of experimental measurements in situ and the material point of view.

The technical expertise revealed apparent corrosion losses in the steel beams that had definitely jeopardised the safety of the construction and its operation. Based on the measurement results regarding corrosion losses and the chemical analyses performed, it is evident that the urban conditions in a synergy with the effects of industrial pollutants negatively affect metal members. Associated with the improper maintenance and operation of the building, its service life and functionality is decreased.

In conclusion, it is to be noted here that the assessment of material degradation in structures plays an important role, is perfectly legitimate and only confirms the significance of multidisciplinary approach towards complex structural analysis taking into account the nature of a particular investigated member. The statics of individual structural members is of primary concern to prevent personnel-safety and health hazards.

\section{Acknowledgments}

The investigation is carried out within the frames of the project VEGA No.1/0788/12: "Theoretical and Experimental Analysis of Stability and Strength of Composite Members in Compression and Bending" of the Grant Agency VEGA of the Ministry of Education of the Slovak Republic and the Slovak Academy of Sciences.

\section{References}

[1] KOCICH, J., SEVCIKOVA, J., TULEJA, S.: Effect of Atmospheric Corrosion on the Mechanical Properties of the Weathering Steel Atmofix 52A. Corrosion Science, vol. 35, 1993, No. 1-4, pp. 719-725. ISSN 0010-938X. 
[2] SEVCIKOVA, J., HALAMA, M.: Studies of Corrosion Resistance of Steel KONOX 315S [in Slovak], Konstrukce, vol. 8, No. 3, 2009, pp. 2-4. ISSN 1213-8762.

[3] SEVCIKOVA, J., HAGAROVA, M., TULEJA, S.: Galvanic Corrosion Studies of Structural Materials Exposed to Influence of Atmosphere, [in Slovak], Acta Mechanica Slovaca, vol. 9, No. 3A, 2005, pp. 159-163. ISSN 1335-2393.

[4] DE LA FUENTE, D., DIAZ, I., SIMANCAS, J., CHICO, B., MORCILLO, M.: Long-Term Atmospheric Corrosion of Mild Steel, Corrosion Science, vol. 53, No. 2, 2011, pp. 604-617.

[5] YUANTAI, MA, YING, LI, FUHUI, WANG: The Atmospheric Corrosion Kinetics of Low- Carbon Steel in a Tropical Marine Environment. Corrosion Science, vol. 52, No. 5, 2010. pp. 1796-1800.

[6] RAMESH KUMAR, A.V., BALASUBRAMANIAM, R.: Corrosion Product Analysis of Corrosion Resistant Ancient Indian Iron, Corrosion Science, vol. 40., No. 7, 1998. pp. 1169-1178.

[7] BALASUBRAMANIAM, R., RAMESH KUMAR, A.V.: Characterization of Delhi Iron Pillar Rust by X-ray Diffraction, Fourier Transform Infrared Spectroscopy and Mossbauer Spectroscopy. Corrosion Science, vol. 42, No. 12, 2000, pp. 2085-2101.

[8] SINGH, D.D.N., YADAV, S., SAHAN, J. K.: Role of Climatic Conditions on Corrosion Characteristics. Corrosion Science, vol. 50, 2008, pp. 93-110.

[9] TERPAKOVA, E.: The Environmental Influence of Flue Dust from the Magnesite Processing on the Building Construction [in Slovak], Acta Montanistica Slovaca, vol, 10, No. 1, pp. 233-235.

[10] KVOCAK, V., BEKE, P., VARGOVA, R., VARGA, G.: Expertise Analysis of Steel Car Park Roof Structure in Kosice [in Slovak], 2011, p. 22.

[11] VARGOVA, R.: Probabilistic Analysis of Reliability and Carrying Capacity of Steel Frame-Structures [in Slovak], Dissertation Thesis. Civil Engineering Faculty, Technical University in Kosice, 2010, p. 193.

[12] STN EN 10029+AC: Hot-rolled Steel Plates 3 mm Thick or Above - Tolerances on Dimensions and Shape [in Slovak], 1998.

[13] STN EN 1090-2:2009: Execution of Steel Structuresand Aluminium Structures - part 2: Technical Requirements for Steel Structures, [in Slovak],

[14] STN EN 1933-1-1:2006: Eurocode 3: Design of Steel Structures - part 1-1: General Rules and Rules for Buildings, [in Slovak]

[15] SEVCIKOVA, J., HAGAROVA, M.: Surface engineering [in Slovak] HF TUKE, 2007, ISBN 9798-80-8073-901-0.

[16] Steel Composition Standard: http://www.zelpo.sk/zelpo/vyrobky.nsf/AtlasoS?OpenPage

[17] VICAN, J., GOCAL, J., MELIS, B., KOTES, P., KOTULA, P.: Real Behaviour and Remaining Lifetime of Bridge Structures. Communications - Scientific Letters of the University of Zilina, vol. 10, No. 2, 2008, pp. 30-37. 